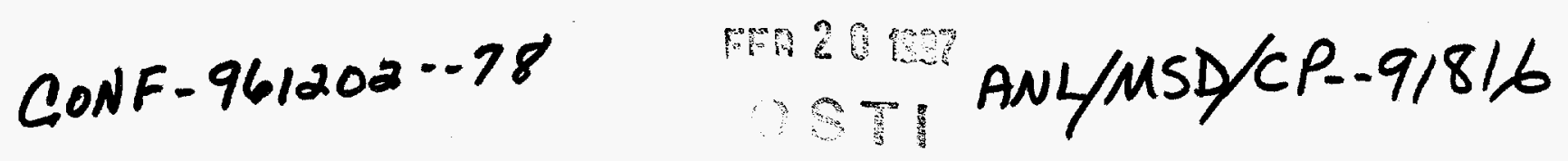

\title{
IN-SITU IRRADIATION STUDIES ON THE EFFECTS OF HELIUM ON THE MICROSTRUCTURAL EVOLUTION OF V-3.8Cr-3.9Ti*
}

\author{
N. Doraiswamy, B. Kestel, and D. E. Alexander \\ Materials Science Division \\ 9700 S. Cass Avenue \\ Argonne National Laboratory \\ Argonne, IL 60439
}

November 1996

The submitted manuscript has been created
by the University of Chicago as Operator of
Argonne National Laboratory ("Argonne")
under Contract No. W-31-109-ENG-38 with
the U.S. Department of Energy. The U.S.
Government retains for itself, and others
acting on its behalf, a paid-up, non
exclusive, irrevocable worldwide license in
said article to reproduce, prepare derivative
works, distribute copies to the public, and
perform publicly and display publicly, by or
on behalf of the Government.

on behalf of the Government publicly, by or

\section{DISCLAIMER}

This report was prepared as an account of work sponsored by an agency of the United States Government. Neither the United States Government nor any agency thereof, nor any of their employees, makes any warranty, express or implied, or assumes any legal liability or responsibility for the accuracy, completeness, or usefuiness of any information, apparatus, product, or process disclosed, or represents that its use would not infringe privately owned rights. Reference herein to any specific commercial product, process, or service by trade name, trademark, manufacturer, or otherwise does not necessarily constitute or imply its endorsement, recommendation, or favoring by the United States Government or any agency thereof. The views and opinions of authors expressed herein do not necessarily state or reflect those of the United States Government or any agency thereof.

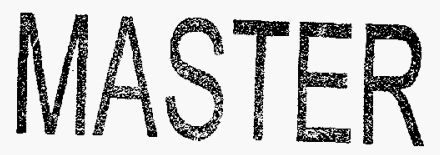

To be submitted to the Materials Research Society Meeting, Boston, MA, December 2-6, 1996.

*Work supported by the U.S. Department of Energy, Basic Energy Sciences-Materials Sciences, under contract
\#W-31-109-ENG-38. 


\title{
IN-SITU IRRADIATION STUDIES ON THE EFFECTS OF HELIUM ON THE MICROSTRUCTURAL EVOLUTION OF V-3.8Cr-3.9Ti
}

\author{
N. Doraiswamy, B. Kestel and D. E. Alexander \\ Materials Science Division, Argonne National Laboratories, Argonne, IL 60439.
}

\begin{abstract}
The role of helium on the microstructural evolution of $\mathrm{V}-3.8 \mathrm{Cr}-3.9 \mathrm{Ti}$ has been investigated by in-situ transmission electron microscopy observations of as-prepared and He implanted $(<10$ appm) samples subjected to $200 \mathrm{keV}$ He irradiation at room temperature. Quantitative analysis of the defects showed an increase in the defect density and size with irradiation in both types of samples. The unimplanted sample showed a defect density consistent with electron irradiation experiments. In comparison, the He preimplanted sample had slightly larger defects and a substantially greater increase in the number density of defects. This result is consistent with a mechanism of He trapping by the formation of He-vacancy-X $(X=C, N, O)$ complexes.
\end{abstract}

\section{INTRODUCTION}

The favorable physical and mechanical properties of $\mathrm{V}-3.8 \mathrm{Cr}-3.9 \mathrm{Ti}$ (wt.\%), when subjected to neutron irradiation, has lead to considerable attention being focused on it for use in fusion reactor structural applications. However, there is limited data on the effects of helium on physical and mechanical properties of this alloy. Understanding these effects are important since helium will be generated by direct $\alpha$-injection or transmutation reactions in the fusion environment, typically at a rate of $\approx 5 \mathrm{appm} \mathrm{He/dpa.} \mathrm{Helium} \mathrm{has} \mathrm{been} \mathrm{shown} \mathrm{to} \mathrm{cause} \mathrm{substantial} \mathrm{embrittlement,}$ even at room temperature in vanadium and its alloys, for example Matsui et al. [1] have shown that there is a drastic reduction in the ductility of pure vanadium with helium addition accompanied by an increase in the yield stress. Recent simulations of the fusion environment using the Dynamic Helium Charging Experiments (DHCE)[2] have also indicated that the mechanical properties of vanadium alloys are altered by the presence of helium in post-irradiation tests performed at room temperature. While the strengths were lower, room temperature ductilities of the DHCE specimens were higher than those of non-DHCE specimens. These changes have been attributed to the formation of different types of hardening centers in these alloys due to He trapping. Independent thermal desorption experiments[3-5] suggest that these hardening centers may be associated with helium-vacancy-X (where $\mathrm{X}=\mathrm{O}, \mathrm{N}$, and $\mathrm{C}$ ) complexes. These complexes are stable below $290^{\circ} \mathrm{C}$ and persist at room temperature. However, there has been no direct microstructural evidence correlating the complexes with irradiation effects. An examination of the microstructure below and above the dissociation temperature $\left(290^{\circ} \mathrm{C}\right)$ would enable such a correlation.

In this paper we report on the results of insitu ion irradiation experiments which show a substantial impact of helium on microstructural evolution during irradiation at room temperature.

\section{EXPERIMENTAL PROCEDURE}

$3 \mathrm{~mm}$ diameter disks were punched from a 10 mil thick sheet of V-3.8 wt.\% Cr-3.9 wt.\% $\mathrm{Ti}$ which had been subjected to a series of extrusion and rolling processes as described elsewhere[6]. The impurity composition of the base alloy is listed in Table I.

Table I : Nominal Composition of the impurities in wppm of the V-3.8 wt.\% Cr-3.9 wt.\% Ti alloy used in this work

\begin{tabular}{llllllllll}
\hline $\mathrm{Cu}$ & $\mathrm{Si}$ & $\mathrm{O}$ & $\mathrm{N}$ & $\mathrm{C}$ & $\mathrm{S}$ & $\mathrm{P}$ & $\mathrm{Ca}$ & $\mathrm{Cl}$ & $\mathrm{B}$ \\
\hline$<50$ & 783 & 310 & 85 & 80 & $<10$ & $<30$ & $<10$ & $<2$ & $<5$ \\
\hline
\end{tabular}

The disks were annealed in an inert $\mathrm{Ar}$ atmosphere for 1 hour at $1050^{\circ} \mathrm{C}$ and subsequently slowly cooled to ambient by removing the sealed ampoule holding the disks from the furnace. The disks were single jet electopolished to thicknesses sufficient for electron transparency using a solution of $85 \%$ methanol and $15 \%$ sulphuric acid at a temperature of $-20^{\circ} \mathrm{C}$. Additional 


\section{DISCLAIMER}

Portions of this document may be illegible in electronic image products. Images are produced from the best available original document. 


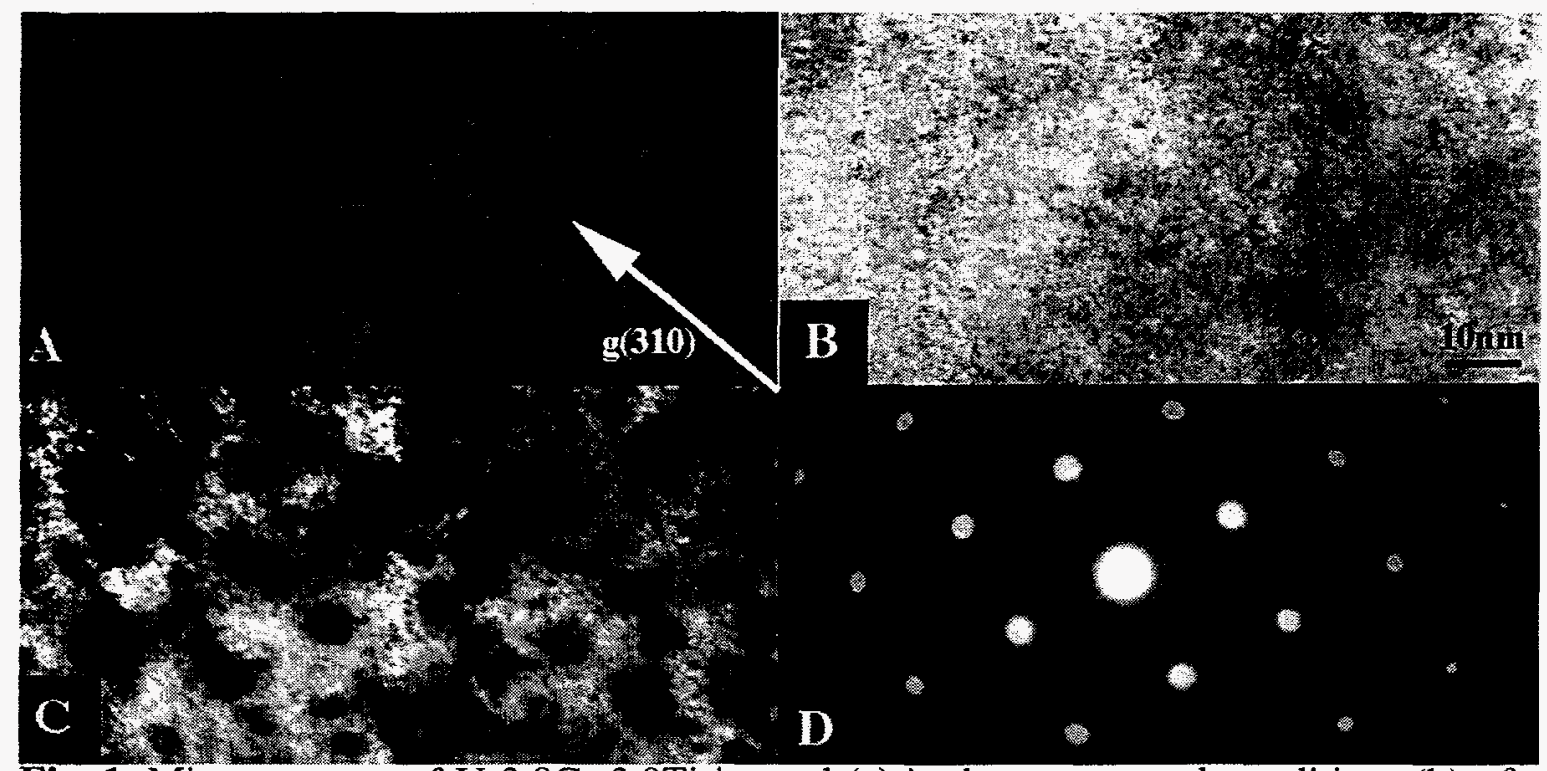

Fig 1: Microstructure of V-3.8Cr-3.9Ti imaged (a) in the as prepared condition, (b) after $40 \mathrm{keV} \mathrm{He} \quad$ preimplantation to $<10 \mathrm{appm}$, (c) after $200 \mathrm{keV} \mathrm{He}$ irradiation to 0.2 dpa and (d) diffraction pattern of 2(c).

processing and experimental observations were conducted insitu at the Intermediate Voltage Electron Microscope (IVEM) operated by the Materials Science Division at Argonne National Laboratory[7]

Microstructural evolution during $200 \mathrm{keV} \mathrm{He}$ insitu irradiation at room temperature in the IVEM was studied in two types of samples. One sample was preimplanted at room temperature with $40 \mathrm{keV} \mathrm{He}$ ions which is the lowest energy practically achievable for He implantation in the IVEM. The He content resulting from this preimplantation, as determined by TRIM[8], appeared to be very sensitive to the sample thickness. Values of $<10$ appm were calculated for a total implantation dose of $2.4 \times 10^{14}$ ions $/ \mathrm{cm}^{2}$ in the implanted sample. The helium implanted sample, as well as an unimplanted sample were subsequently irradiated with $200 \mathrm{keV} \mathrm{He}$ at a damage rate of $1.2 \times 10^{-5} \mathrm{dpa} / \mathrm{sec}$ (also evaluated using TRIM), in damage increments up to $0.2 \mathrm{dpa}$.

Two-beam dark field microstructural imaging was perfomed at each damage increment studied. The best imaging, in which the defects were most clearly resolved, was accomplished in a

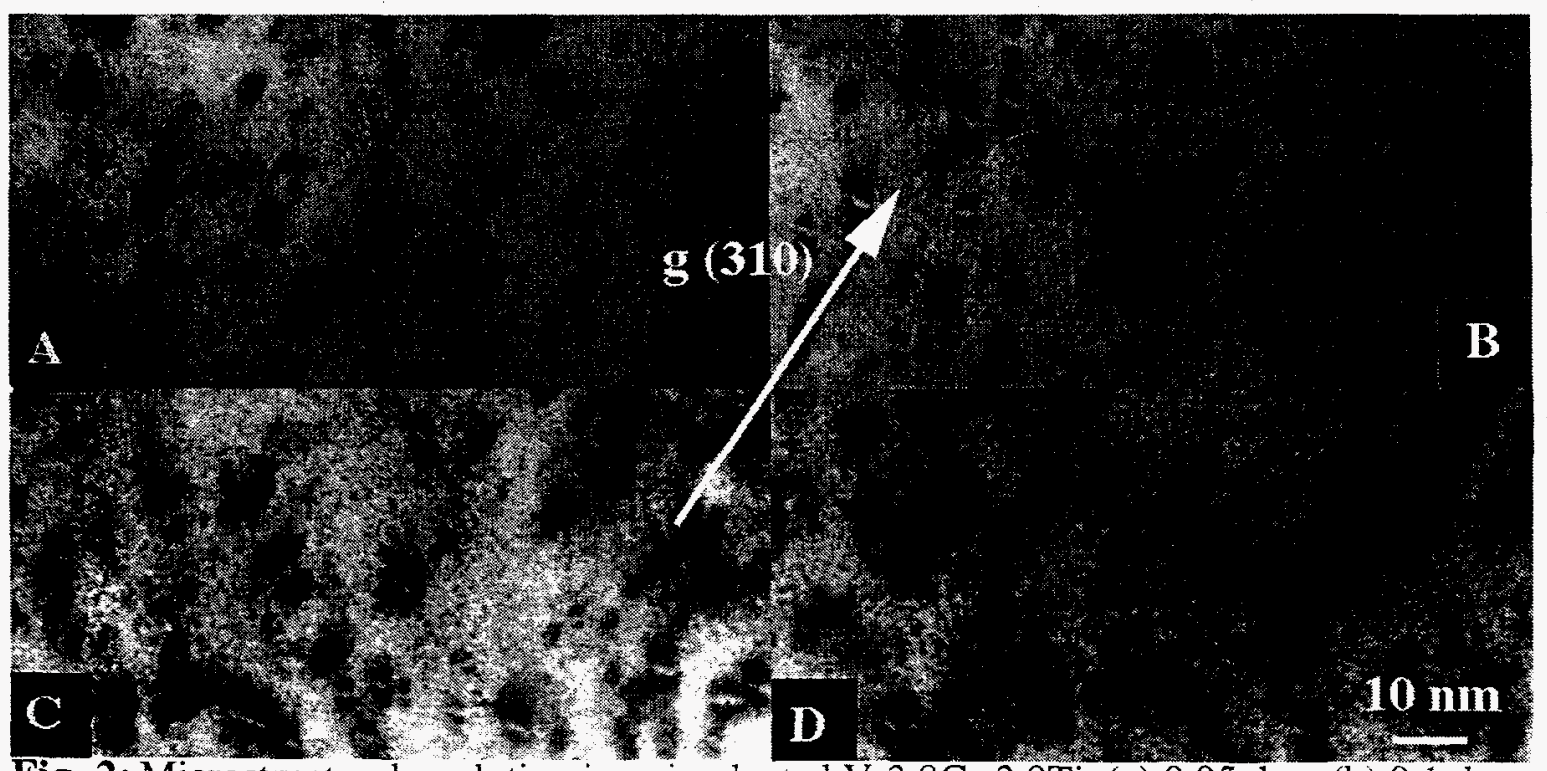

Fig 2: Microstructural evolution in unimplanted $\mathrm{V}-3.8 \mathrm{Cr}-3.9 \mathrm{Ti}$. (a) $0.05 \mathrm{dpa}$, (b) $0.1 \mathrm{dpa}$ (c) 0.15 dpa and (d) 0.2 dpa 
(310) orientation. While all the orientations gave rise to a black, white defect contrast, only two of the orientations, the (211) and the (310), clearly showed a black-black lobe defect structure which can be unambiguously resolved and measured. Therefore all the quantitative analysis was performed using microstructural images acquired in the (310) two-beam condition.

The microstructure was analyzed by digitizing the TEM images recorded at $100 \mathrm{kx}$ at a final resolution of $0.168 \mathrm{~nm}$ per pixel using a Leafscan -45 . The digitized images were further processed by manually marking the diameter of the defects using Adobe Photoshop. The areal defect density (defects per unit area) was determined using $\mathrm{NIH}$ image. The defect concentrations were obtained by dividing the areal densities by the sample thickness obtained via low loss electron energy loss spectroscopy (EELS) measurements calibrated with convergent beam electron diffraction (CBED) measurements. The foil thickness, in increments of electron mean free path, were evaluated from the areas under the low loss peaks [9] in the EELS spectrum with an error of about $\pm 20 \%$. The electron mean free path used in these calculations was determined by CBED measurements[10] to be $98 \mathrm{~nm}$.

Some limited post irradiation energy dispersive spectroscopy (EDS) was conducted on these samples using the ANL-AAEM VG603Z scanning transmission electron microscope to determine the chemical composition of the various features in the samples.

\section{RESULTS AND DISCUSSION}

Fig. 1(a-c) shows microstructural changes following various treatments used in this study. After $40 \mathrm{keV} \mathrm{He}$ implantation [fig.1(b)], no significant changes (including bubble formation) were observed. After $200 \mathrm{keV} \mathrm{He}$ irradiation [fig. 1(c)], new features appear in the microstructure attributable to defect formation. The defect nature of these features is confirmed by the absence of additional reflections in diffraction from the sample that would indicate precipitation of a separate phase. Furthermore, through-focal series imaging failed to reveal any helium bubbles.

A limited number of small probe EDS measurements in the unimplanted specimen indicated that the defects were slightly enriched in S; a contaminant likely resulting from the jet thinning process. A film of $\mathrm{C}$ was also detected on the sample surface. A simple test involving irradiation of a sample that was prepared with a non-acid solution revealed that the same defects formed even in the absence of S. Since all the samples were prepared in the same fashion, these contaminants were expected to be equally present in each of the samples studied.

Microstructural evolution in an unimplanted sample in the range of 0.05 to $0.20 \mathrm{dpa}$ is shown in fig. 2. The series shows an increase in the size and, to a lesser degree, the number density of defects with increasing damage. A quantitative representation of the size evolution is
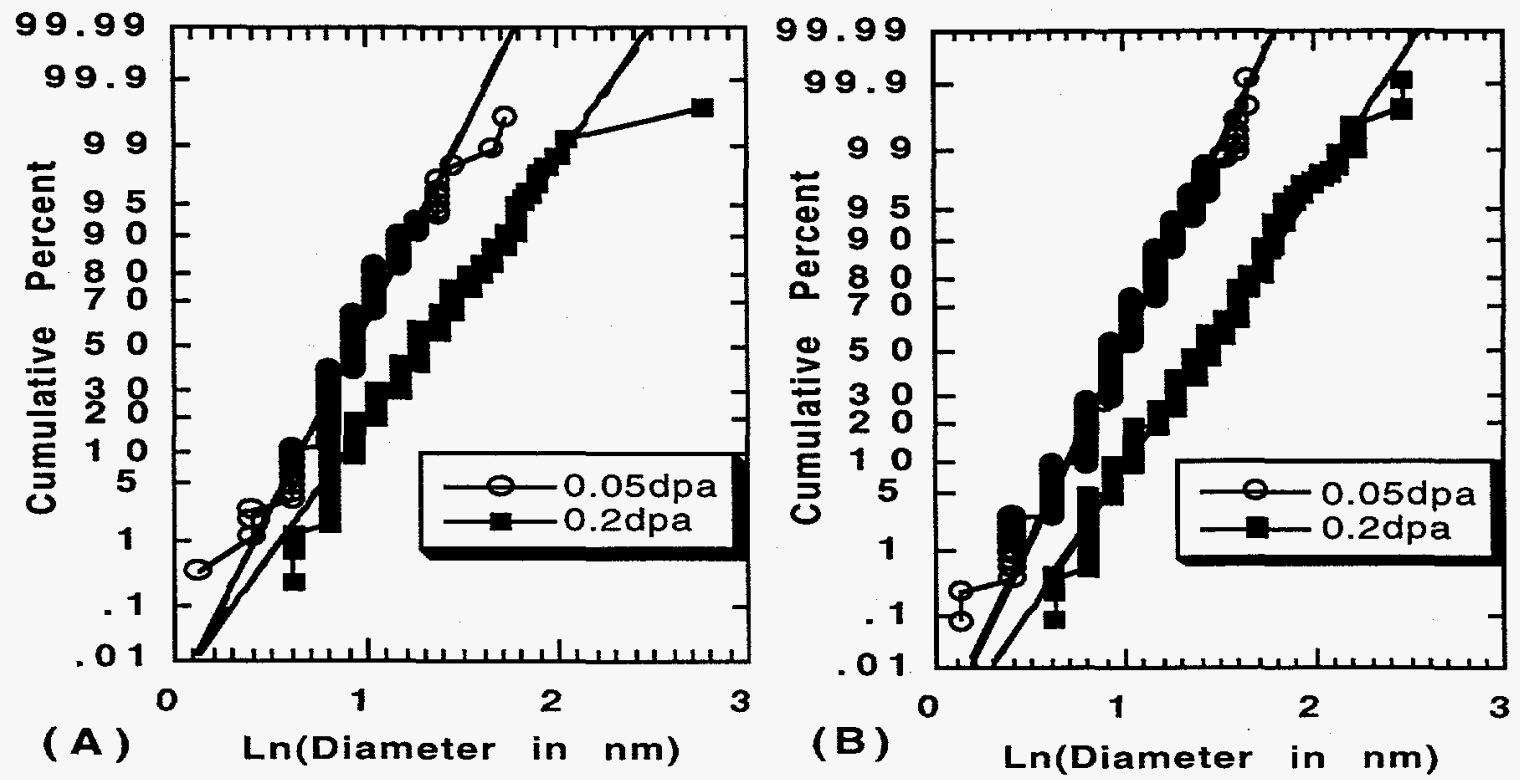

Fig 3: Typical defect size distributions for the (a) unimplanted sample and (b) He preimplanted after $200 \mathrm{keV}$ irradiation 


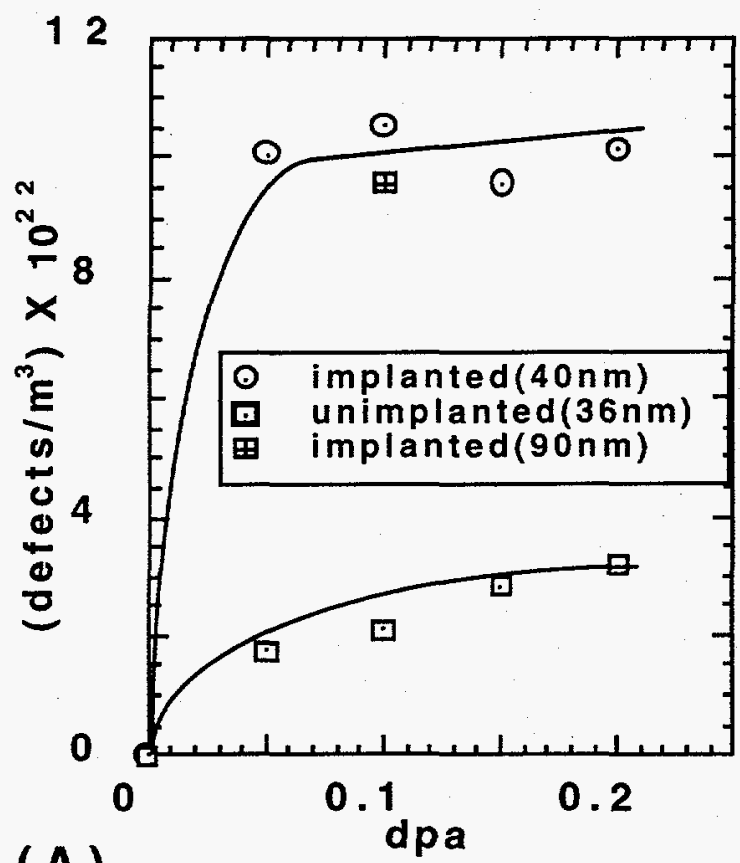

(A)

Fig 4: A comparison of (a) number density and (b) mean defect size for He preimplanted (40nm thick) and unimplanted ( $36 \mathrm{~nm}$ thick) samples and that of a $90 \mathrm{~nm}$ thick He preimplanted sample. The lines were drawn to guide the eye.

given by the defect size distributions displayed in fig. 3 for both implanted and unimplanted samples. As seen in fig. 3, the defect sizes were lognormally distributed and the decreasing slope of the linear fits indicate a broadening in the size distributions at higher damage levels.

The number densities of defects measured in the unimplanted sample (see fig. 4) were consistent with the temperature dependent trend in saturated interstitial loop densities measured previously by Nishizawa et al.[11] during $1 \mathrm{MeV}$ electron irradiation of $\mathrm{V}-4 \mathrm{Ti}-4 \mathrm{Cr}$ alloy. Extrapolation of their elevated temperature measurements to room temperature yields a saturated defect density of about $2 \times 10^{22}$ defects $/ \mathrm{m}^{3}$ similar to the values observed in the unimplanted sample shown in fig. $4 a$.

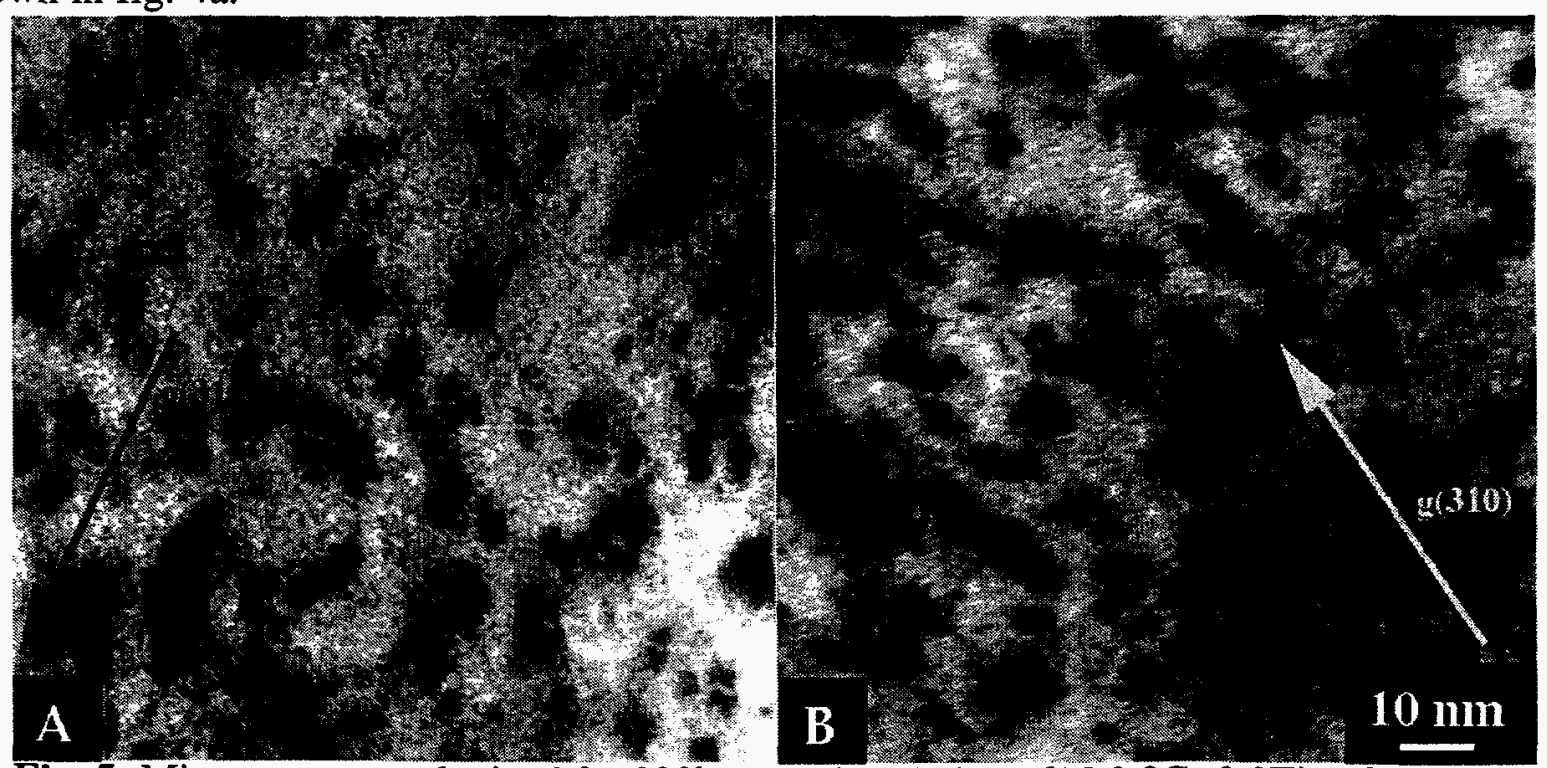

Fig 5: Microstructures obtained for $200 \mathrm{keV}$ He irradiation of V-3.8Cr-3.9Ti to $0.15 \mathrm{dpa}$, in similar thickness regions in an (a) unimplanted (36nm thick) and (b) Hepreimplanted(40nm thick) samples. 
A substantial effect of the small amount of He preimplantation is observed through comparison of the microstructures shown in fig. 5. In samples irradiated to the same dpa, the He preimplanted sample [fig. 5(b)] clearly exhibits a higher number density of defects relative to the unimplanted sample [fig. 5(a)]. This diffierence is confirmed by the quantitative analysis summarized in fig. 4(a) which shows about a factor of five increase in the number density. A less dramatic increase in mean defect size was also observed [fig. 4(b)] for the He preimplanted samples. However, the size difference may be due to a sample thickness effect. This was demonstrated by a microstructural analysis performed on a thicker ' $(90 \mathrm{~nm})$ region of the preimplanted sample irradiated to $0.1 \mathrm{dpa}$. In the thicker region, the mean defect size increased by $50 \%$ over that observed in the thinner $(40 \mathrm{~nm})$ region of the same sample. Hence the slight defect size differences observed between the unimplanted and implanted specimens, as displayed in in fig. 4(b), may be due to the thickness difference in the regions analyzed ( $40 \mathrm{~nm}$ versus $36 \mathrm{~nm}$ ). In contrast, the defect number density measured in the thicker region of the implanted sample did not vary significantly from that observed in the thinner region [see fig. 4(a)]. Therefore a thickness effect on number density may be discounted.

\section{CONCLUSIONS}

The large increase in the defect number density caused by He preimplantation as observed in this work is consistent with the formation of He-vacancy- $X(X=C, N, O)$ complexes whose presence alter the interstitial-vacancy populations during irradiation and thus alter the final microstructure. However, consideration of the role of $S$ contaminants, as well as surface $C$ film detected by EDS, may be necessary to completely understand the microstructural differences.

\section{ACKNOWLEDGEMENTS}

The authors thank N. J. Zaluzec for his helpful discussions and the aid in the chemical analysis, we also thank the members of the IVEM facility at ANL, L. Funk, E. Ryan and S. Ockers for their help. Further the support of the DOE-BES and DOE/OFE under contract \#W-31-109-ENG-38 is gratefully acknowledged.

\section{REFERENCES}

1. H. Matsui, M. Tanaka, M. Yamamoto, and M. Tada. J. Nuc. Mater. 1992 191-194. p 919. 2. H.M. Chung, B.A. Loomis, L. Nowicki, and D.L. Smith. Fusion Reactor Materials, Semiannual. Prog. Rep. 1995. ORNL, Oak Ridge, TN.DOE/ER-0313/19.

3. A. Van Veen, H. Eleveld, and M. Clement. J. Nuc. Mater. 1994 212-215. p 287

4. A.I. Ryazanov, V.M. Manichev, and W. Van Witzenburg. J. Nuc. Mater. 1996 227. p 304.

5. A.V. Fedorov, G.P. Buitenhuis, A. Van Veen, A.I. Ryazanov, J.H. Evans, W. Van Witzenburg, and K.T. Westerduin. J. Nuc. Mater. 1996 227. p 312.

6. H.M. Chung, H.C. Tsai, D.L. Smith, R. Peterson, C. Curtis, C. Wojcik, and R. Kinney. Fusion Reactor Materials, Semiannual Prog. Rep. 1994 ORNL, Oak Ridge, TN DOE/ER$0313 / 17$.

7. C.W. Allen, L.L. Funk, and E.A. Ryan. Mater. Res. Soc. Symp. Proc.1996 396. p 641.

8. J.F. Ziegler, TRIM-The Transport of Ions in Matter[Ver. 92] (Yorktown, NY: IBM Res.).

9. R.F. Egerton and S.C. Cheng. Ultramicroscopy 1987 21. p 231.

10. P.M. Kelly, A. Jostsons, R.G. Blake, and J.G. Napier. Phys. Stat. Sol. (a) 1975 31. p 771. 11. T. Nishizawa, H. Sasaki, S. Ohnuki, T. Shibayama, and H. Kayano. in International symposia on Adv. Mater. Tech. for the 21st century. The 117th meeting of JIM. 1995. Honolulu. 